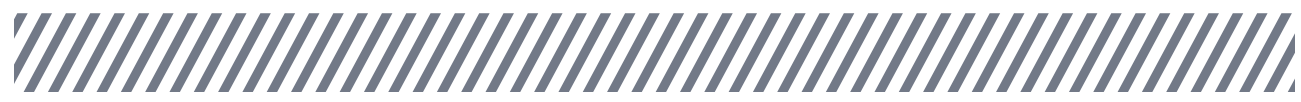

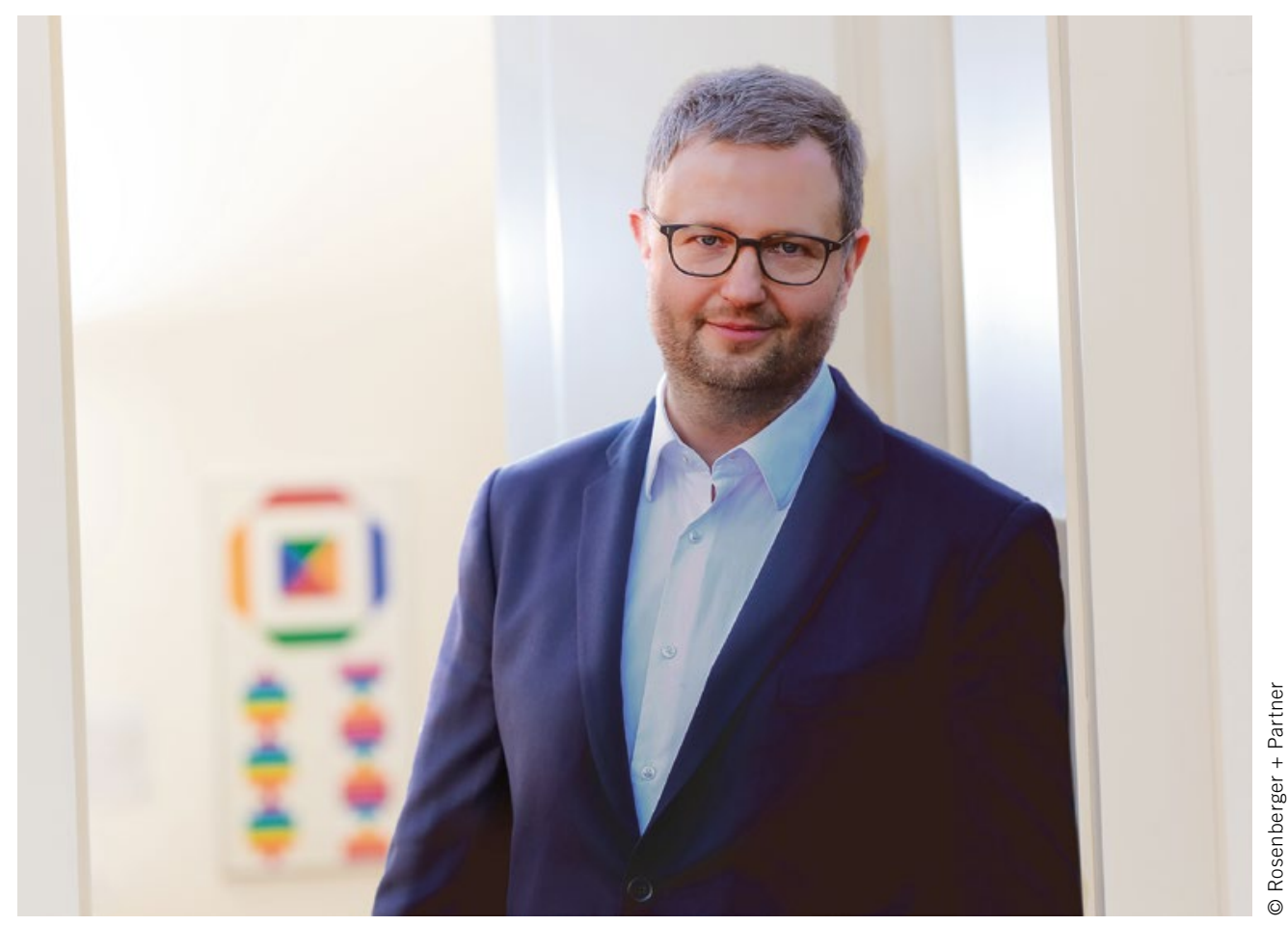

Matthias Hintz

Partner bei Rosenberger + Partner

\section{Die zweite passende Brille}

Was braucht es neben fachlichen Kompetenzen, um als Ingenieur in Teams und Organisationen erfolgreich zu sein - ob als Fachexperte oder in einer führenden Rolle?

Die Antwort vorweg: Es braucht neben der technischen Sicht auch den richtigen Blick auf sich selbst, andere, Teams und Organisationen, also eine zweite passende Brille. Menschen und soziale Systeme (Teams, Organisationen) folgen nämlich einer anderen Logik als technische Systeme. Trotzdem wird häufig der Fehler begangen, die technische Brille und die damit verbundenen Prinzipien auch auf Menschen und soziale Systeme anzuwenden - leider auch von vielen Beratern. Zahlreiche individuelle und organisationale Change-Projekte scheitern unter anderem deshalb. Zwei wesentliche Aspekte unterscheiden beide Systemarten.

Erstens: Menschen und soziale Systeme können nicht von außen verändert werden. Sie können sich nur aus sich selbst heraus verändern. Ein Coach kann keinem, der Angst hat, vor Publikum zu sprechen, von außen angstfrei machen. Es ist nur möglich, den Prozess zu begleiten, der zu einer inneren Veränderung führt.

Zweitens: Menschen und soziale Systeme folgen keiner verdrahteten Logik und sind damit nicht von außen erklär- und vorhersehbar. Sie folgen ihrer Eigendynamik. Jedoch bilden diese Systeme veränderbare Muster aus. Zum Beispiel werden in einem Team kritische Wahrnehmungen nicht angesprochen.
Ingenieure agieren in einem Kontext von Menschen und sozialen Systemen. Um erfolgreich zu sein, benötigen sie auch Kompetenzen, die über das reine Fachwissen hinausgehen. Hier einige davon, jenseits der üblich genannten Soft Skills:

- Kenntnis der unterschiedlichen Systemarten: Welche Brille muss ich aufsetzen, um Relevantes beobachten und wirksam handeln zu können? Hier bietet das Cynefin-Framework von Dave Snowden eine gute erste Orientierung.

- Damit Menschen und soziale Systeme sich von innen heraus verändern können, ist es wichtig, sich der eigenen Muster bewusst $\mathrm{zu}$ werden. Ingenieure, die die eigenen Muster sowie die von anderen, von Teams und Organisationen wahrnehmen und in die Kommunikation einbringen können, sind begehrte Allrounder. Dies gilt umso mehr für die Arbeit mit agilen Methoden wie etwa Scrum.

- Die richtige Einordnung dieser Muster setzt das Grundverständnis voraus, wie Menschen und soziale Systeme ticken. Denn jedes Muster hat eine Funktion, einen Sinn. Hier benötigen Ingenieure eine Orientierung gebende, kompakte Weiterbildung, die sie auf sich selbst und in ihrer Praxis anwenden können.

- Schließlich brauchen sie eine innere Sicherheit im Umgang mit der äußeren Unsicherheit. Ein technisches System ist beherrschbar und planbar - nicht so Menschen und soziale Systeme. 